\title{
Inequality in employment trajectories and their socio-economic consequences during the early phase of the COVID-19 pandemic in Germany
}

Katja Möhring ${ }^{\text {a* }}$, Andreas Weiland ${ }^{\text {a }}$, Maximiliane Reifenscheid ${ }^{\text {a }}$, Elias Naumann ${ }^{\text {a }}$, Alexander Wenz ${ }^{\text {a }}$, Tobias Rettig ${ }^{\text {a }}$, Ulrich Krieger ${ }^{\text {a }}$, Marina Fikel ${ }^{\text {a }}$, Carina Cornesse ${ }^{\text {a }}$, Annelies G. Blom ${ }^{\text {a }}$

${ }^{a}$ Collaboartive Research Center 884 "Political Economy of Reforms", University of Mannheim, Germany

* Corresponding author, E-mail: moehring@uni-mannheim.de

Katja Möhring is Assistant Professor for Sociology of the Welfare State at the School of Social Sciences, University of Mannheim

Andreas Weiland is Doctoral Researcher at the School of Social Sciences and the Collaborative Research Center SFB 884, University of Mannheim

Maximiliane Reifenscheid is Doctoral Researcher at the Collaborative Research Center SFB 884, University of Mannheim

Elias Naumann is Post-Doctoral Researcher at the Collaborative Research Center SFB 884, University of Mannheim

Alexander Wenz is Post-Doctoral Researcher at the Collaborative Research Center SFB 884, University of Mannheim

Tobias Rettig is Doctoral Researcher at the Collaborative Research Center SFB 884, University of Mannheim

Ulrich Krieger is Post-Doctoral Researcher at the Collaborative Research Center SFB 884, University of Mannheim

Marina Fikel is Researcher at the Collaborative Research Center SFB 884, University of Mannheim

Carina Cornesse is a Post-Doctoral Researcher at the Collaborative Research Center SFB 884, University of Mannheim

Annelies G. Blom is Professor for Data Science at the School of Social Sciences, University of Mannheim 


\section{Abstract}

This paper evaluates the inequalities in employment trajectories during the first COVID-19 pandemic lockdown in Germany. We assess individual-level panel data collected weekly between 20 March and 25 June $(\mathrm{N}=2,297)$, which allows us to examine the risks of short-time work, furlough, and job loss, as well as changes between working on-site and from home. Using sequence analysis, we detect typical patterns of employment trajectories and analyse how these vary between socio-demographic groups. Finally, we relate the types of employment trajectories to changes in income, subjective job security (compared to values in January and February 2020), and COVID-19 infection risks. Our results show clear gradients in employment risks: low-wage workers were severely affected by furlough and job loss, while highly qualified employees were able to work from home. Furthermore, in contrast to previous crises, service sector and female employees were more affected by short-time work; however, its timing and duration differs compared to male workers in manufacturing. Income loss was pronounced among those who became unemployed and those continuously in short-term work, while everybody - including employees continuously working from home-experienced a significant reduction in subjective job security compared to employees whose employment hours or location have not changed. The infection risk was only increased for individuals who changed from furlough to working on-site.

Key words: Lockdown; Remote work; Short-time work; Job Security; Sequence Analysis

Acknowledgements: We thank Omid Soroush for support and the participants of the Virtual ISA-RC28 conference on Social Stratification under the Coronavirus Pandemic for helpful comments. We are grateful to the Collaborative Research Center SFB 884 "Political Economy of Reforms" (Deutsche Forschungsgemeinschaft, grant number: 139943784) for financial and general support. The Mannheim Corona Study has been in addition partially funded by the Network for Interdisciplinary Social Policy Research (FIS.00.00185.20). 


\section{Introduction}

The COVID-19 pandemic and the containment measures have had fundamental and immediate effects on economies and labour markets all over the world (Daly et al., 2020; Lejeune, 2020). Its employment consequences are not fully understood yet, and seem to differ from those of previous recessions, also due to the service sector, and especially women, being disproportionally affected (Alon et al., 2020; Anger et al., 2020; Blundell et al., 2020; Möhring et al., 2020; Naumann et al., 2020). The pandemic and the containment measures have introduced three main changes to individuals' working lives, each of which has potentially tremendous consequences for employees. First, many companies have experienced a loss of revenue and orders since the onset of the pandemic. The main social policy instrument to avoid mass lay-offs during economic crises in Germany is the short-time work arrangement, which allows companies to reduce their employees' working hours and wages in times of economic hardship or when production is impaired. A government earnings replacement scheme then compensates the wage loss partially (Konle-Seidl, 2020; Wachter, 2020). In a second change, the pandemic represents the greatest homeworking experiment in history (Felstead and Reuschke, 2020), as many companies in Germany and other countries switched to remote working and obliged their employees to work from home. Third, a widespread (but less regulated) response to the pandemic has been to suspend employees - so-called furlough. Furloughed workers in Germany do not receive any government earnings replacement to compensate for their loss of income.

Our study analyses inequality in employment trajectories, covering all three changes and their consequences for employees. It draws on weekly information on the employment situation of individuals in Germany that covers the first COVID-19 lockdown and several weeks after. The data come from a special COVID-19 survey 
carried out as part of the German Internet Panel (GIP), which is a representative longitudinal survey of the German population (Blom et al., 2015, 2020). In a first step, we use sequence analysis to identify patterns of employment trajectories during the early phase of the pandemic and their distribution among the workforce according to socio-demographic characteristics. In a second step, we relate the identified types of employment trajectories to consequences for perceived job security, income, and infection risk. Thereby, we address three main questions related to employment inequality in a pandemic recession. What were the dynamics of typical employment pathways in the early phase of the crisis? Which groups in the labour market have been most affected in terms of their working life, income, and infection risk? How do employment transitions translate into feelings of insecurity? To the best of our knowledge, our study is the first to use detailed weekly longitudinal data to analyse how employment trajectories and related inequalities have evolved during the first COVID19 lockdown period.

The article is organised as follows. We first set out the theoretical background and place our analysis in the wider frame of research on the dualization of labour markets. This includes describing the segmentation of Germany's pre-pandemic labour market and the government's crisis measures. We next describe the data set, the operationalisation of variables, and the methods applied. We then present the results and discuss the implications for further research and social policy.

\section{Background}

\section{Labour market inequality and policies in Germany}

Germany has a coordinated market economy with a labour market and labour laws that have traditionally provided a high level of protection for employees, which created a 
high-wage and low-inequality economy during the post-war period (Bothfeld, 2007; DiPrete, 2016; Hall and Soskice, 2001). In recent decades, however, the country’s labour market has become increasingly polarised between a primary sector that offers high employment protection and high earnings on the one hand, and a secondary sector with insecure employment relationships and low wages on the other hand (Emmenegger, 2012; Garz, 2013; Schwander and Häusermann, 2013). Labour market inequality increased since the early 1990s due to an expanding low-wage sector and growing disparities between educational groups (Dustmann et al., 2009), and further intensified after the labour market reforms of the early 2000s, which included the flexibilisation of the low-wage sector and cuts in earnings-replacement benefits for long-term unemployed persons (Eichhorst and Marx, 2011). These changes caused inequality to rise further, especially due to increased polarisation between full-time and part-time employees in terms of wages and job security, de facto constituting a gender divide as mostly women work part time in Germany (Bosch and Weinkopf, 2008; Brülle et al., 2018; Häusermann and Schwander, 2012). As a consequence, Germany currently has one of the highest shares of the female workforce in low-wage employment in Europe (Eurostat, 2020).

The link between institutional divides embedded in the social security system and inequality in union coverage have reinforced the dualization of the German workforce (Hassel, 2014). While workers in the industrial sector are covered by union agreements that guarantee steady pay rises and job protection, low-wage workers in the service sector are poorly protected outsiders. Stagnating wages in the service sector compared to manufacturing since the 1970s have also contributed to these polarisations; relative wage losses have been especially pronounced in the hospitality sector. As Hassel (2014: p. 72) explains: 
$[\ldots]$ manufacturing and low skilled service sector firms now work under different institutional regimes. Manufacturing is organized around a body of skilled high productivity core workers which is protected against economic insecurity. Low skilled services operate under conditions that are similar to labour markets in liberal market economies.

In summary, the main divisions in the German workforce are gender and level of education, which is partly mirrored in divergencies between economic sectors (Hassel, 2014; Häusermann and Schwander, 2012).

Yet, the polarisation on the German labour market goes beyond the servicemanufacturing divide, constituting a division in three segments. First, the unstructured segment includes low-skilled positions filled by employees with no vocational or university qualifications and typically follow highly volatile job trajectories with short tenures and frequent job changes (Blossfeld and Mayer, 1988; Kalina, 2012). These jobs are typically located in the secondary segment of the service and industrial sector, including low service functionaries and blue-collar workers (Schwander and Häusermann, 2013). Second, the occupational segment corresponds with the structure of the vocational training system and offers jobs following a technical (e.g., skilled craft workers) or organizational (e.g., routine office workers) work logic. Third, high-skilled professionals and managers in the primary segment of internal labour markets typically enjoy well-paid, secure employment relationships with access to internal career ladders and seniority-based payment. This internal segment includes experts and executives in large manufacturing companies, public administration, and in the service sector, e.g. in information and technology (Häusermann and Schwander, 2012; Kalina, 2012). 


\section{Government crisis measures}

Crisis measures such as the short-time work benefits have a long-standing tradition in Germany and have been successful at preventing mass lay-offs in previous economic crises. The goal of short-time work is to enable employers to reduce their employees' working hours without having to lay them off in the event of an economic downturn or temporary loss of orders (Wachter, 2020). Employers, rather than individual employees, apply for this short-time work status; working hours can be reduced flexibly, and can even be set to zero. The short-time work benefit compensates for 60 percent of employees' earnings losses (67 percent for those with children) based on their previous net income (Konle-Seidl, 2020). This benefit is intended to be a temporary measure, restricted to a maximum duration of 12 months; its success therefore depends on how long the economic crisis lasts (Fischer and Schmid, 2020).

Rueda $(2012,2014)$ argues that government crisis measures align with existing divisions in the labour market. Labour market insiders not only have a better position, as they typically work in higher-paying, more secure jobs; they also enjoy better protection in the social security system. Importantly, workers in low-wage employment up to 450 Euro monthly pay are not eligible for the short-time work benefit, nor are previously subcontracted workers usually eligible, but in the pandemic crisis the shorttime work allowance has been temporarily expanded to include the latter.

Germany suffered fewer job losses during the Great Recession than many other countries (Rinne and Zimmermann, 2012). The negative consequences of the crisis were rather short term and mainly concentrated in male-dominated, export-oriented industrial sectors, such as the automotive industry. The short-time work policy described above helped prevent mass lay-offs in the industrial sector, as did other state subsidies designed to boost domestic demand (Burda and Hunt, 2011). By contrast, employment in the service sector increased even in the core crisis years, which involved rising 
employment rates of women in part-time and atypical employment (Kirchmann and Rosemann, 2010). Hence, the government crisis measures' focus on male-dominated sectors did not have further consequences at that time.

The German federal government has adopted several measures to lessen the employment effects of the COVID-19 pandemic. It prolonged the short-time work benefits to up to 24 months or the end of 2021 and enacted a temporary increase to 70 percent ( 77 percent) of the net wage after four months and 80 percent ( 87 percent) after seven months (BMAS, 2020). A public aid package including direct payments for companies that experienced income shortfalls was launched during the spring lockdown. Nevertheless, the economic aid package has been criticised for again largely focusing on male-dominated sectors of the economy (Wiesner, 2020).

\section{Vulnerability in the COVID-19 pandemic}

When analysing social inequality in employment during the pandemic, in addition to economic vulnerability, which includes negative consequences such as job loss or reduction of working hours and earnings (Schwander and Häusermann, 2013), health vulnerability has to be considered, namely the risk of COVID-19 infection. Therefore, individuals' ability to determine their working arrangements constitutes a central aspect of inequality. This applies first and foremost to the choice of the work location. For employees with care responsibilities, having the flexibility to determine their working time becomes more relevant in a pandemic crisis with schools and day cares closed.

First, we explore how the distribution of economic risks throughout the workforce during a pandemic crisis differs from previous economic recessions. Due to the sudden introduction of containment measures in March 2020, jobs in the service sector that involve personal contact (restaurant and hospitality sector, retail, culture and entertainment sector, and household-related services) were suspended. The use of the 
short-time work benefit is limited in these fields due to the large number of ineligible employees and self-employed sole traders in precarious positions. Therefore, the pandemic has hit employees in precarious service sector positions especially hard (Grabka et al., 2020). While manufacturing was not affected by the immediate shutdown, the implementation of containment measures in factories may narrow production capacities. The mid- and long-term consequences for the industrial sector depend on the development of domestic demand and export, i.e. on how much consumption in Germany and on worldwide markets declines during the crisis. Consumption of products may increase as demand for services decreases as a result of the stay-at-home policies. Therefore, it is likely that employees in the service sector, especially low-wage workers, experienced more immediate and more severe harm than in previous crises. With respect to more long-term consequences of the employment distortions induced by the pandemic recession, early research for the UK and Germany shows that short-time work and furlough are associated with poorer prospects for future job security (Adams-Prassl, Boneva, et al., 2020; Möhring et al., 2020).

Second, we have to ask how the infection risk as second dimension of vulnerability is distributed in the workforce. Employees' ability to determine their own working time and location is greatest among the highly qualified workforce in the internal segment of the service sector. Workers in the occupational segment often perform tasks that cannot be done remotely (Adams-Prassl et al., 2020; Felstead and Reuschke, 2020). Furthermore, research on remote work before the pandemic highlighted gender differences: women generally have fewer opportunities to work from home even when it would be technically possible (Lott and Abendroth, 2020). Early analyses on potential vs. actual homeworking during the pandemic have shown that the chances of homeworking are indeed unevenly distributed among the workforce: highly 
qualified employees are more likely to work from home (Adams-Prassl et al., 2020; Felstead and Reuschke, 2020). Although the group of homeworkers is still selective, selectivity may have been reduced during the lockdown given that the containment measures were imposed with little or no notice. For example, early research on working from home during the pandemic suggests that the previous gender gap seems to have narrowed (Möhring et al. 2020). However, it is unclear how sustainable these changes are. Therefore, from a long-term perspective, inequality might also emerge from the pace of returning to work on-site after containment measures are eased.

\section{Hypotheses}

As in previous crises, labour market insiders are less vulnerable to negative employment outcomes than outsiders. The economic decline in the current pandemic crisis will lead firms to first lay off employees in the "unstructured segment" of the labour market, in both the industrial and service sectors. Workers in the internal segment, who have greater flexibility to determine their work arrangements, will have more possibilities to work from home during the lockdown. Therefore, we assume that those with lower educational degrees and in low-wage employment are most affected by the negative consequences of the crisis (that is, being in short-term work or furloughed), while those with higher educational degrees and high wages are more able to work from home (Hypothesis 1).

In contrast to the Great Recession, the service sector has been at least as hard hit as the industrial sector and has experienced negative consequences much more immediately due to the containment measures in the current pandemic crisis. This has implications for the effect on gender inequalities, as more women work in the service sector. Therefore, we expect that women are hit by the crisis effects earlier and are 
equally affected as men by the negative consequences of the pandemic (Hypothesis 2). However, since in the service sector more employees are in marginal employment and are thus not eligible to receive short-time work benefits, the crisis effects in the two sectors might still differ. Therefore, we assume that short-term work is most often used in the occupational segment of the labour market, while low-wage employees face higher risks of furlough and job loss (Hypothesis 3).

We also expect the consequences of the crisis to diverge in terms of timing for different groups in the labour market. Highly qualified workers from the internal segment will have greater long-term access to compensation and protection from the state or government, while others will be more exposed to the ups and downs of the crisis. Therefore, we assume that short-time work and furlough in the unstructured segment of the service sector is more transient (Hypothesis 4) and that among those initially working from home, less qualified employees and women return more quickly to working on-site (Hypothesis 5).

With respect to the economic and health outcomes of employment trajectories during the first lockdown, we expect that being affected by short-term work and especially furlough leads to a decrease in subjective job security, while subjective job security should be the same between employees working on-site vs. from home (Hypothesis 6). The infection risk should be highest among those who continuously work on-site (Hypothesis 7).

\section{Materials and methods}

\section{Data and operationalisation}

We use data from the GIP, which is based on a random probability sample of the general population of Germany aged 16 to 75 . The panel started in 2012 and was 
supplemented with additional participants in 2014 and 2018. The panel participants were recruited offline using strict statistical procedures (Blom et al. 2015). Every other month, panel participants are invited to take part in a voluntary online survey. The GIP launched a special survey on 20 March 2020 to gather data about the COVID-19 pandemic. GIP panelists were invited to take surveys every week. In the descriptive analysis we use weights to account for attrition and non-response in this special pandemic survey (compared to the usual GIP sample) and apply weights to extrapolate participants' characteristics to those of Germany's general population based on age, gender, marital status, highest level of education, household size, and federal state. We include only individuals who were employed in January 2020 and are below 68 years old $(\mathrm{N}=2,297)$.

We operationalise the employment situation based on information on employment status and location of work and differentiate five categories: work usual hours on-site, work usual hours from home, short-time work, furlough, and unemployment. Please note that in the German context, only those in short-term work are eligible for state top-up benefits as described above; furlough means being suspended from work without receiving state benefits (unlike Britain's temporary furlough scheme; Adams-Prassl, Boneva, et al., 2020). Furloughed employees, however, may receive continued pay from their employer.

As explanatory variables for the cluster composition we include gender (female, reference category: male); a dummy variable for migration background (no German citizenship or not born in Germany); and a dummy variable for poor health based on subjective health status (reference category: partly good/partly bad, good, excellent health). To measure educational degree we distinguish between low (without or with basic school-leaving qualification), middle (intermediate school-leaving qualification), 
and high (higher education entrance qualification). In addition, we divide occupational sectors into three categories (industry, service, public administration/education/health, other) and personal net income into three categories (below 1,000 Euro, 1,000-2,500 Euro, above 2,500 Euro). These income categories refer to the 25 and 75 percent quartiles of the income distribution in the GIP, yet this is a rough estimate as income was measured in 15 categories. All variables are measured before the onset of the pandemic.

As cluster outcomes we consider the change in household income between February and June 2020, the change in self-assessed unemployment risk between January and July 2020, and COVID-19 infection. Household income is a continuous measure composed of 15 categories; income changes are operationalised as household income in June subtracted from household income in February. Respondents' future job security is operationalised with their subjective assessment of the likelihood of job loss in the next 12 months; the measure is composed of five categories ranging from very low to very high. We use the change in this indicator operationalised with the value from early July subtracted from the value measured before the onset of the pandemic in January. The measure of COVID-19 infection is composed of two elements. The first is a question asking whether the respondent had received a confirmed positive test result. The second was a question to everybody who had not taken a test asking them to subjectively assess whether they had been infected. We combine positive test results (weighted 1.69 percent of the sample) with the answer "Yes, I am pretty sure" from the second question (weighted 1.07 percent of the sample) to operationalise a confirmed or very likely COVID-19 infection ( $\mathrm{N}=52)$. Appendix Table A.1 provides an overview of all variables. 


\section{Methods}

Our analysis proceeds in three steps. We first apply sequence analysis to obtain a holistic understanding of the employment trajectories between 20 March and 25 June 2020. This method is used to assess the (dis-)similarity of trajectories in order to identify and visualise typical groups (Abbott, 1995). We treat respondents' employment trajectories as sequences with 14 elements, representing the 14 weeks of our observation window, which are categorised as one of five employment states. Applying an optimal matching algorithm with Dynamic-Hamming distances and a cost structure based on empirical transition probabilities leads to an element-wise comparison of each possible sequence pair in the data. The resulting dissimilarity matrix serves as the input for a hierarchical cluster analysis (Piccarreta and Billari, 2007). Here, we identify eight distinct clusters of employment trajectories. Sequence and cluster analysis were applied in R, utilising the TraMineR package (Gabadinho et al., 2011).

To analyse the composition of the employment trajectory clusters-in other words, to determine which socio-demographic characteristics are associated with cluster membership — we use multinomial logistic regression models with the sequence clusters as the dependent variables. We apply the same type of regression models to analyse the outcomes of the clusters, with independent variables measured at the end of our observation window.

\section{Results}

\section{Descriptive overview}

Figure 1 illustrates how the weekly employment situation of those who were in gainful employment in January 2020 changed over the course of the lockdown. The main phase of the first lockdown started with contact restrictions on 22 March, which included an 
immediate shutdown of restaurants, shops — apart from grocery stores — and recreation and similar personalised services. Gatherings and cultural events were banned, and only meetings with members of one's own household or with one person from another household were allowed. The containment measures were relaxed starting on 6 May to allow shops and restaurants to reopen; leisure sports and recreational activities were allowed again. A lighter version of the contact restrictions was in place until 5 June. Schools and day care facilities were completely closed from 13 March and reopened stepwise at different time points in the federal states between late April and early May. Schools did not completely reopen until June; in some federal states they reopened after the summer break. Day care centres were mostly closed until at least mid-June.

Figure 1. Employment situation on a weekly basis, percentage of persons who were employed in January 2020

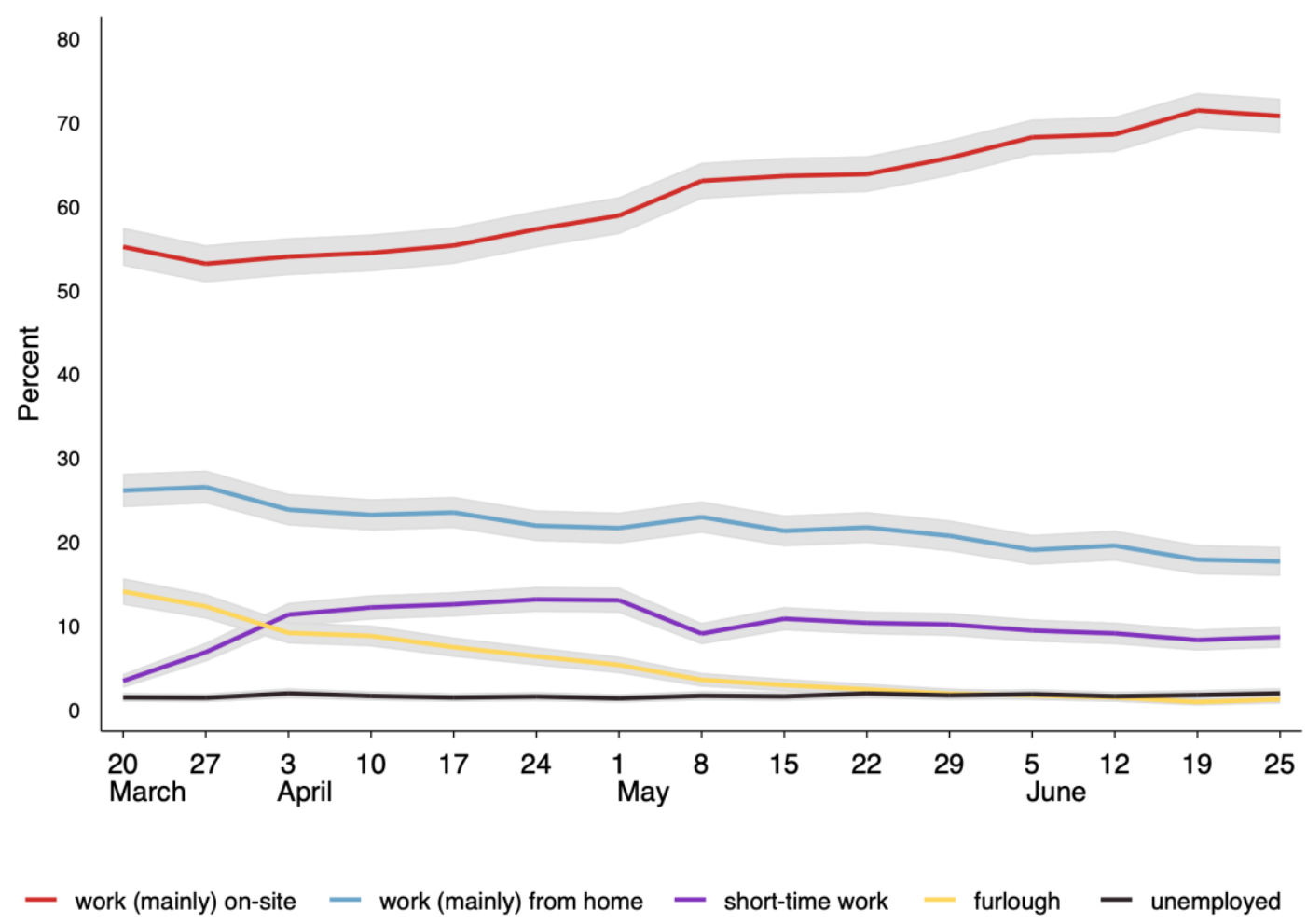

Source: German Internet Panel, own estimations. 
Despite these unprecedented measures, the majority of employed persons continued to work their usual hours, on-site, during the whole observation window: the percentage increased from around 50 percent in late March and early April to 70 percent in late June. A quarter of employees were working from home during the early phase of the lockdown, which represents a significant increase from before the onset of the pandemic: in January 2020 only around 11 percent of employees worked from home at least part of the time. In the week of 20-26 March, 3.4 percent of employees reported that they were receiving the government short-time work allowance; this number climbed to over 12 percent in mid-May. In the following weeks, the share of short-time work decreased again to around 7 percent at the end of our observation window. The downward trend in short-time work coincides with the reopening of shops and restaurants in late April. During the first weeks of the lockdown, 10-14 percent of those employed in January were furloughed; of them around one-third were suspended without pay; the rest received continued pay. Furlough was mainly a transitional state, as the share dropped to below 2 percent in late June. The share of people who have lost their job since January 2020 has remained below 5 percent. As 3.27 percent of the workforce in Germany becomes unemployed over a three-month span in usual times, these transitions may not be entirely attributed to the pandemic (Sozialpolitik-aktuell, 2020a, 2020b).

\section{Sequence analysis of employment trajectories}

Figure $2 \mathrm{a}$ shows the state distribution plots and Figure $2 \mathrm{~b}$ the sequence index plots for the eight clusters, and Table 1 gives an overview of the socio-demographic composition of the clusters. Clusters 1 to 3 contain trajectories of individuals who continued to work in their job with usual hours over the whole lockdown period. 
Figure 2a. State distribution plots of the employment trajectory clusters Figure 2b. Sequence index plots of the employment trajectory clusters
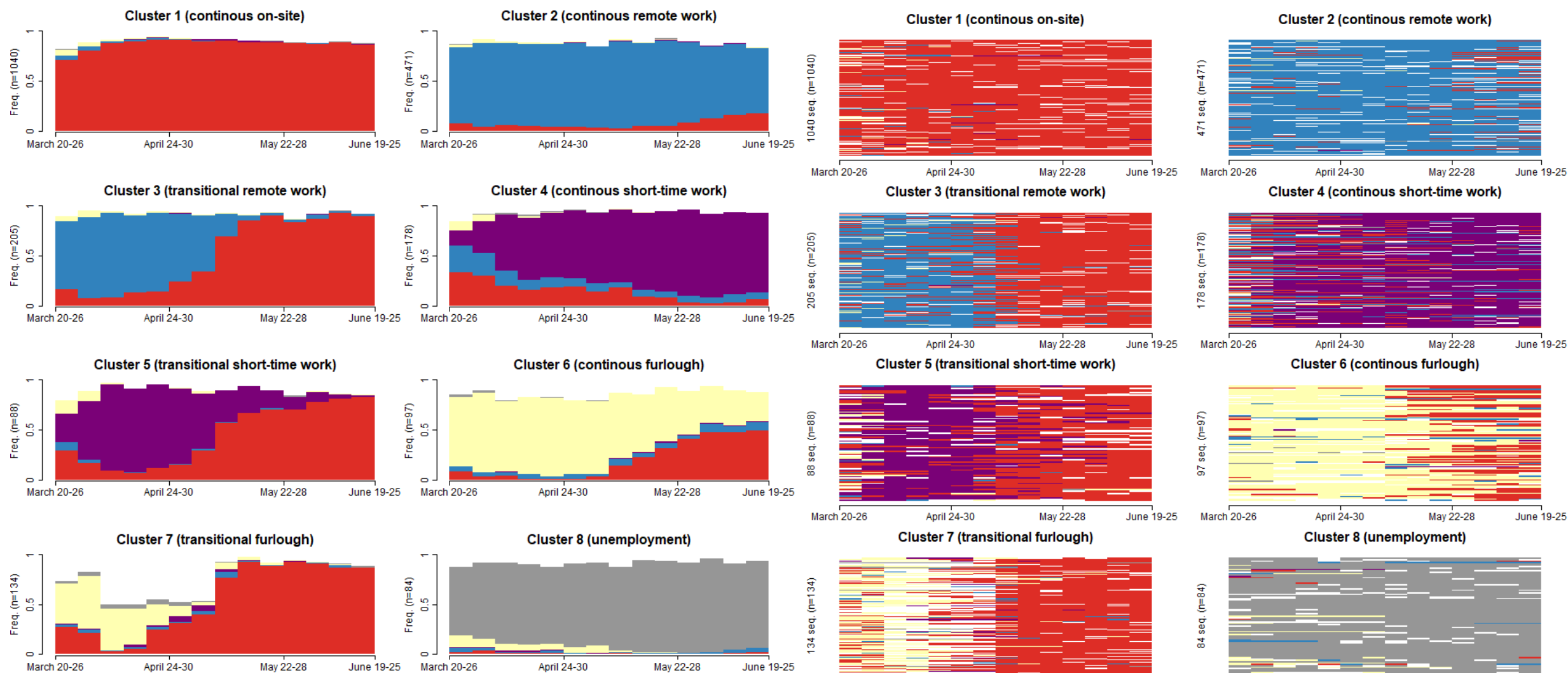

Cluster 4 (continous short-time work)
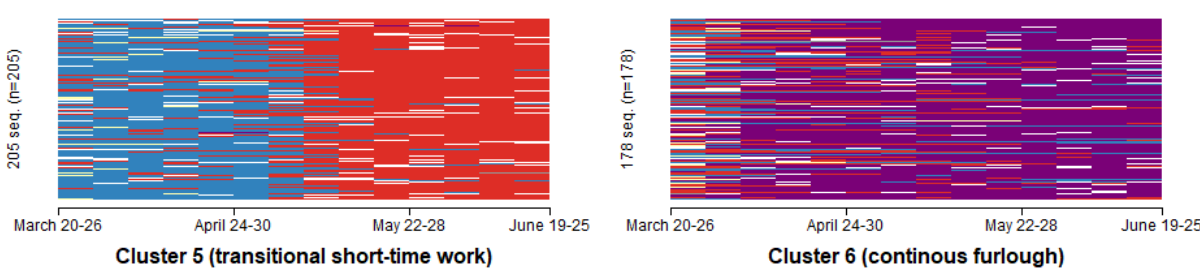

Cluster 5 (transitional short-time work)
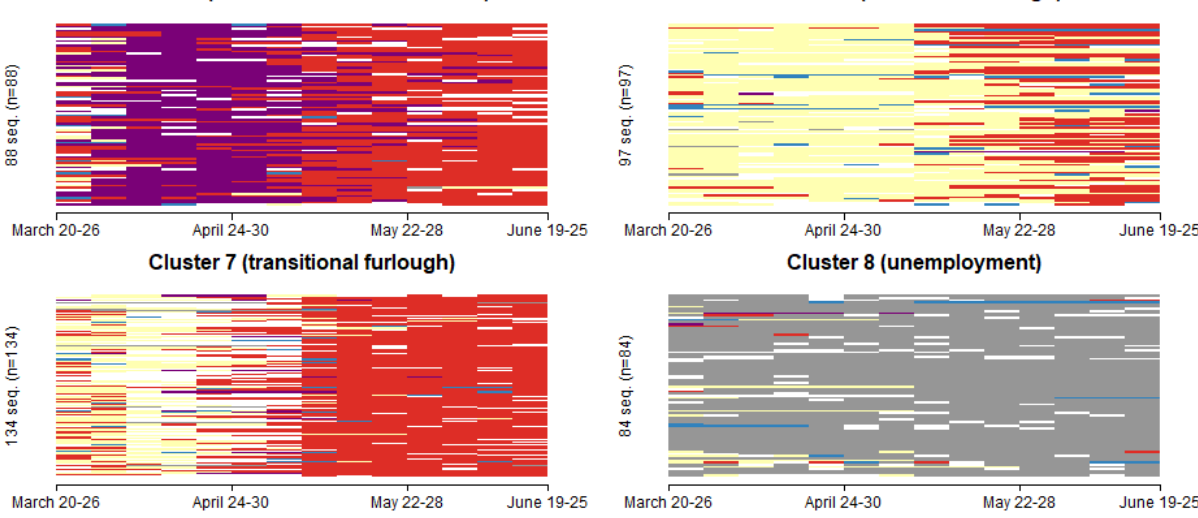

$\begin{array}{ll}\text { Dork on-site } & \text { 品 furlough } \\ \text { remote work } & \text { 品 unemployed } \\ \text { short-ime work } & \text { no information }\end{array}$

Source: German Internet Panel, own estimations.

\section{\begin{tabular}{ll}
\hline - work on-site & 品 furlough \\
remotot work \\
short-time work
\end{tabular}}

Source: German Internet Panel, own estimations.

(c) (1) 
Table 1: Descriptive overview of cluster composition by socio-demographic characteristics

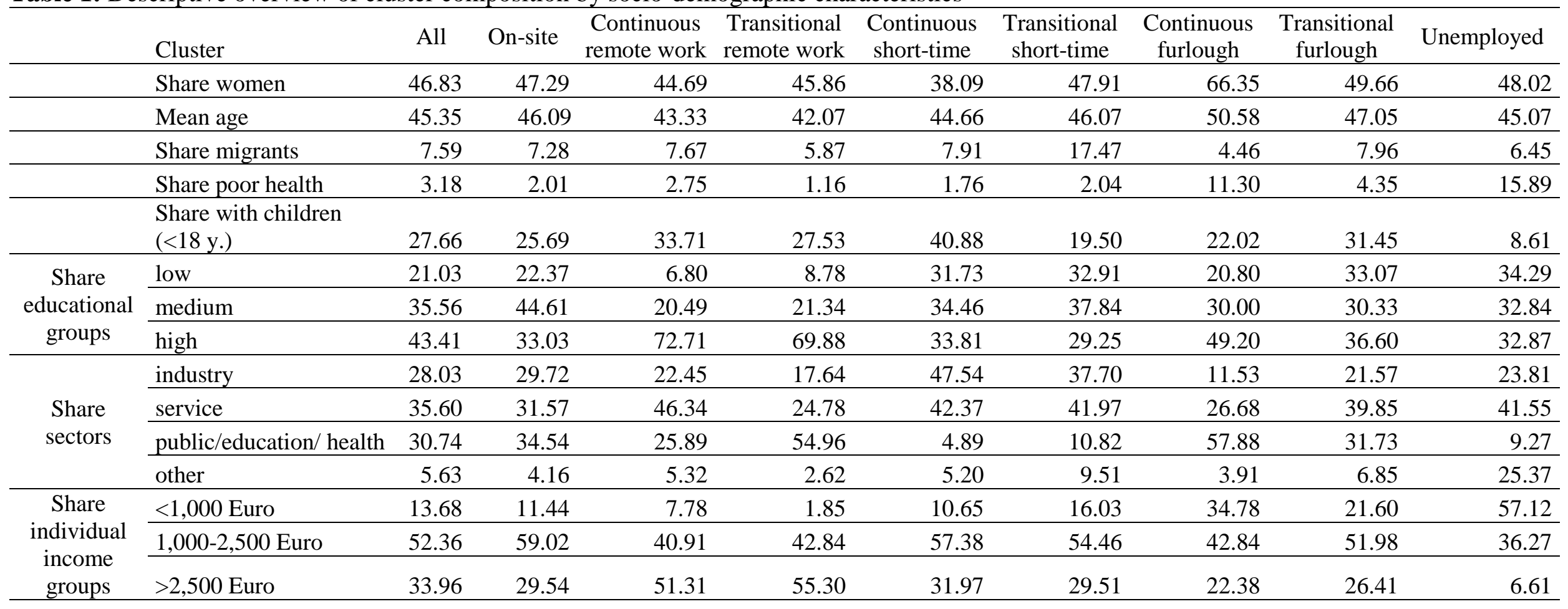

Source: German Internet Panel, own estimations. 
The majority (Cluster 1; $\mathrm{N}=1,040$ ) continued to work on-site. The second-largest group almost continuously worked from home (Cluster 2; $\mathrm{N}=471$ ), and a smaller fraction changed from remote work to working on-site during the middle of the observation period (Cluster 3; N=205). Those working continuously or initially from home mainly have a high educational degree and high pay before the outbreak of the pandemic, whereas those continuously working on-site in Cluster 1 mainly have a vocational degree and medium pay. Low-wage workers are underrepresented in all three clusters.

Four further clusters contain individuals who had reduced working hours or completely interrupted working. Individuals in Cluster $4(\mathrm{~N}=178)$ were continuously in short-time work until the end of the observation period, but changed to this status somewhat later than those in Cluster 5. Cluster $5(\mathrm{~N}=88)$ of transitional short-time work contains individuals who changed to short-time work immediately after the onset of the lockdown, and then returned to their usual working hours in early May. Both short-time clusters deviate strongly in their gender and sectoral composition. While the share of female workers is average in the cluster of transitional short-time work (Cluster 5), which is roughly evenly distributed between industry and the service sector, female representation is very much below average in the cluster of continuous short-time work (Cluster 4), which mainly affects industrial sector workers. Both clusters also differ in their educational composition: while both clusters contain mainly workers with occupational degrees, people in the lowest educational group are overrepresented in the cluster of transitional short-time, but underrepresented in the cluster of continuous short-time.

People who were furloughed during the observation period are included in Clusters 6 and 7. Individuals in Cluster $6(\mathrm{~N}=97)$ were continuously on furlough, while those in Cluster $7(\mathrm{~N}=134)$ were in transitional furlough, returning to their usual 
working hours in about early May. The share of female workers is above average in both furlough clusters, and both contain above-average shares of workers with previously low earnings. The continuous furlough cluster is highly polarised in terms of educational composition, as it features above-average shares of employees in the lowest and highest educational groups. This cluster also has a higher mean age and an above average share of individuals with poor health, indicating that people at a higher risk of severe illness in case of COVID-19 infection accumulate in this cluster.

Lastly, Cluster $8(\mathrm{~N}=84)$ contains individuals who are or became unemployed during the course of the lockdown. Nearly all of those individuals transitioned to unemployment at or shortly after the onset of the lockdown, or in the time between the GIP interview in January and the first interview of the COVID-19 survey at the end of March. Therefore, the majority of these transitions into unemployment may not be attributed to the COVID-19 pandemic.

\section{Multivariate analysis of cluster composition}

We use multivariate analysis, with the clusters as dependent variables, to assess the relationship between different characteristics of the cluster composition. For example, we explore whether the overrepresentation of men or women in some clusters can be explained by their sectoral composition. Figure 3 and Appendix Table A.2 report the results of the multinomial logit models, the figure focuses on selected coefficients. Cluster 1, which includes those who continuously worked on-site, serves as the reference category. Figure and table show relative risk ratios, which denote the "risk" of belonging to a certain cluster relative to the reference category of Cluster 1; values below 1 indicate a lower probability, and above 1 a higher probability. 
Figure 3. Coefficient plots of the multinomial logit regressions for cluster composition, relative risk ratios for selected coefficients (full regression results in Appendix Table A.2)
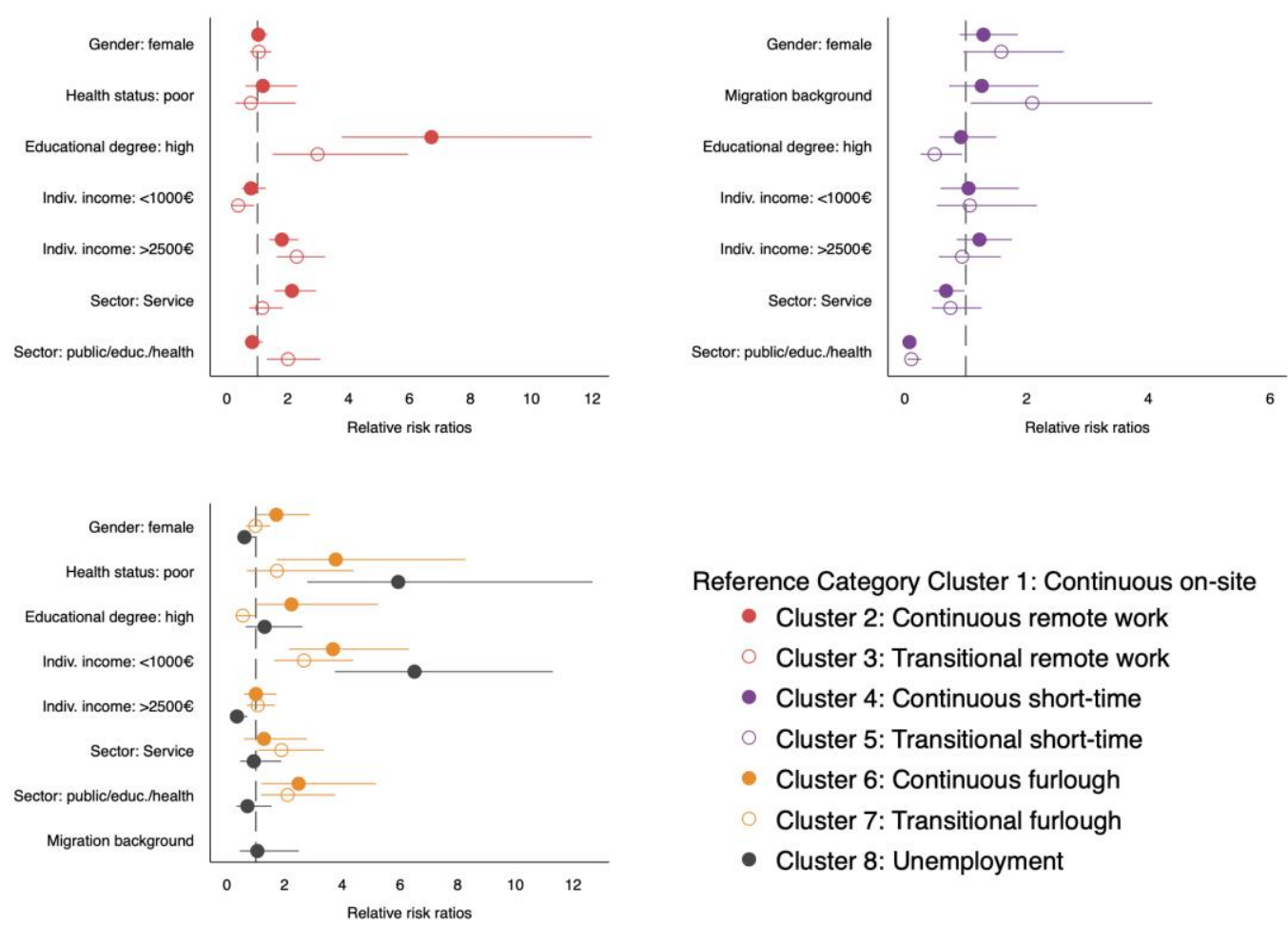

Source: German Internet Panel, own estimations.

Membership in Cluster 2 (continuously working from home) is significantly related to a high educational degree, working in the service sector, and having a high personal income. Individuals with high educational degree have an almost 600 percent increased probability of belonging to this cluster compared to Cluster 1 , for members of the service sector the probability is 113.2 percent higher, and for those with high earnings it is 80.3 percent higher. Although women are slightly underrepresented in this cluster, gender differences are not significant after controlling for sector and previous income. Cluster 3 (transitionally working from home) has a significant, two times higher share of employees in public administration and the education and health sectors, an almost three times higher share of individuals with a high educational degree, and a 128.9 percent higher share of employees with high earnings. Hence, in addition to the 
sectoral differences, for the cluster of transitional remote work the income gradient is steeper, while for the cluster of continuous remote work the educational gradient is steeper. Older employees have a lower probability of belonging to either of the two homeworking clusters, while poor health is not related to working from home. Hence, homeworking does not appear to be more common among those at a higher risk of severe illness in case of COVID-19 infection; it is instead a privilege of highly educated high earners in specific areas of the service and public sectors.

With respect to the composition of Cluster 4 (continuous short-time work) and Cluster 5 (transitional short-time work), it is especially interesting which factors are not significant. First, there are no significant differences between genders in either cluster membership. Second, short-time work does not seem to be restricted to specific educational or income groups. It instead appears to be highly sector specific: employees in the industrial sector have a higher chance of being in continuous short-time work than those in the service and public sectors. For transitional short-time, there are no significant differences between the service and industrial sectors. Third, the risk of being in continuous in short-time work decreases with age, and employees with migration background have a more than two times higher risk to be in transitional shorttime work.

Employees with low earnings have a higher chance of being continuously or transitionally furloughed (Cluster 6 and 7). Employees who earned below 1,000 Euro in monthly net income before the pandemic were 3.7 times more likely to be continuously furloughed and 2.7 times more likely to be transitionally furloughed compared to the middle-income group. Continuous and transitional furlough mainly occur in public administration and the education and health sectors. Women have a higher chance of being continuously furloughed because they are overrepresented in low-income jobs. 
Furthermore, the risk of being continuously furloughed is almost four times higher for employees with poor health, and this risk increases with age. In Cluster 8

(unemployment), the income gradient is even more pronounced than in the two furlough clusters; those with previously low earnings having a significant 6.5 times higher risk of job loss. Furthermore, for those with poor health, the risk of being unemployed is almost 5.9 times higher, even more than being continuously furloughed.

\section{Cluster outcomes}

Table 2 reports the results of the multinomial logit models with the clusters as dependent variables. Again, the largest cluster (Cluster 1) - those continuously working on-site - serves as the reference category. In all regressions we control for cluster composition in terms of gender, age, and educational degree. Model 1 incudes changes in household income and COVID-19 infection, and Model 2 adds the subjective risk of job loss (we therefore exclude Cluster 8 , unemployed, from this model).

Table 2: Multinomial logit regressions for employment trajectory cluster outcomes, relative risk ratios, controlling for gender, age, and educational degree

\begin{tabular}{lcc}
\hline Reference group: Continuous on-site & $(1)$ & $(2)$ \\
\hline Continuous remote work & 1.052 & 1.077 \\
Household income change February-June & $(1.19)$ & $(1.54)$ \\
& & \\
COVID-19 infection: confirmed or very likely & 0.837 & 1.173 \\
& $(-0.33)$ & $(0.29)$ \\
Job loss risk change February-June & & $1.446^{* *}$ \\
& & $(3.25)$
\end{tabular}

Transitional remote work

Household income change February-June

1.053

COVID-19 infection: confirmed or very likely

Job loss risk change February-June

-Table 2 continued on next page- 
-Table 2 continued-

Continuous short time

Household income change February-June

$0.832^{* *} \quad 0.896^{+}$

$(-3.27)$

COVID-19 infection: confirmed or very likely

$1.111 \quad 1.289$

$(0.18) \quad(0.38)$

Job loss risk change February-June

$2.482^{* * *}$

(6.54)

\section{Transitional short time}

Household income change February-June

0.883

0.891

$(-1.58)$

COVID-19 infection: confirmed or very likely

1.195

1.668

$(0.23)$

$(0.65)$

Job loss risk change February-June

\section{Continuous furlough}

Household income change February-June

0.865

0.889

$(-1.53)$

COVID-19 infection: confirmed or very likely

Job loss risk change February-June

\section{Transitional furlough}

Household income change February-June

COVID-19 infection: confirmed or very likely

Job loss risk change February-June

\section{Unemployment}

Household income change February-June

COVID-19 infection: confirmed or very likely

0.000

$(-0.02)$

\begin{tabular}{lcc}
\hline $\mathrm{N}$ & 1,739 & 1,432 \\
Pseudo-R sq. & 0.0520 & 0.0690 \\
\hline
\end{tabular}

Notes: Exponentiated coefficients; $z$ statistics in parentheses $;{ }^{+} p<.1,{ }^{*} p<.05,{ }^{* *} p<.01,{ }^{* * *} p<.001$ Source: German Internet Panel, own estimations. 
We find that employees continuously in short-time work, in transitional furlough, and unemployed experienced a significant reduction in their household income between February and June; these relationships remain significant after controlling for cluster composition. Short-time workers lost 16.2 percent more of their income between February and June compared to the reference group; for those in transitional furlough the reduction is 15.2 percent, and for unemployed individuals it is 13.1 percent. As the latter two groups comprised a high share of low-wage earners before the onset of the pandemic, this income reduction is especially severe for them.

Compared to those continuously working on-site, almost all other employees perceived their job security as lower; the lowest values were found in the two short-time clusters (Model 2). Both perceived their risk of becoming unemployed in the next year as more than 2 times higher than workers without a change in working hours or location. Employees in the two furlough clusters experienced 1.7 times higher subjective job insecurity than members of Cluster 1. Interestingly, those who continuously worked from home were also significantly more concerned about losing their job than employees working continuously on-site, even though the former group comprises mostly highly educated high earners. Only employees who transitionally worked from home and then returned to working on-site displayed no significant increase in subjective unemployment risk compared to those continuously working onsite.

Lastly, we analyse whether cluster membership is related to different probabilities of COVID-19 infection (Model 1). Overall, we find no significant differences between the employment clusters, apart from the transitional furlough cluster: employees in this group have a significant 4.7 times higher risk of confirmed or very likely infection compared to Cluster 1 . 


\section{Discussion and conclusion}

We have examined how the employment trajectories of workers in Germany were affected during the early phase of the COVID-19 pandemic, the lockdown and containment measures, and how this aligns with existing inequalities in the country's labour market. Indeed, the immediate employment consequences mirror the existing segmentation of the labour market in a much more pronounced way than in previous recessions. Employees in the occupational segment experienced the fewest changes as they predominantly continued to work on-site with their usual hours. Highly educated employees in the internal segment of the service sector are to a larger extent in the privileged position of being able to work from home. Employees in low-wage employment in the service sector were particularly negatively affected by furlough and job loss. Short-time work was more likely among employees in manufacturing, but it is not restricted to certain wage or educational groups. In summary, Hypotheses 1 and 3 are largely supported, as those with lower educational degrees and in low-wage employment were indeed more affected by continuous furlough and job loss. Short-time work, however, is more diversely distributed, not only among the middle segment of manufacturing as assumed in Hypothesis 3.

By applying sequence analysis, we are able to shed more light on the dynamics of employment trajectories. For all three states (working from home, short-time work and furlough), we identify two groups: (1) the state is persistent over the whole observation period and (2) the state is transitional - those affected returned to working their usual hours on-site in late April to early May when the containment measures were eased. These two groups differ not only in the timing of their employment transitions, but also in their socio-economic composition and outcomes. While those in continuous short-time work are similar to short-time workers in previous recessions-male 
industrial workers with medium incomes - the group of transitional short-time workers during the COVID-19 recession is much more diverse; it includes more women, migrants and service sector employees. Generally, working from home is predominant among highly educated, high-income employees. However, the educational gradient is more pronounced for continuous homeworking, which is more widespread in the private service sector; transitional homeworking is more widespread in the public sector. Being female, in the low-wage sector, and having an adverse health condition is associated with a higher risk of being continuously furloughed. The social gradient is not as strong for transitional furlough, although also here low-wage earners are overrepresented. Also, those in transitional furlough are the only group with an increased risk of COVID19 infection. However, we cannot determine the extent to which this can be attributed to their work. In summary, for low-wage employees in the service sector, short-time work is mostly transitional, while continuous short-time work is more common among industrial workers in the middle segment of the labour market, which supports Hypothesis 4. Contrary to Hypothesis 5, however, those who return to working on-site after initially working from home are by no means lower paid and lower qualified than other homeworkers.

Taking into account the dynamics of employment transitions also helps us to identify gender differences. In the pandemic recession, women were almost equally affected by short-time work as men; however, women entered short-time work earlier and for them it was more transitional. Of course, employees in the lower segment of the service sector were immediately hit by the containment measures, but returned to their usual working hours after the restrictions were eased. Yet, this also means that their position is much more fragile and may change quickly when new stay-at-home orders are imposed. Overall, the results on gender differences support Hypothesis 2-that 
women were at least equally affected by the negative employment consequences of the pandemic. The more transitional nature of employment consequences for (female) employees in the lower segment of the service sector is in line with Hassel's (2014) assessment that the conditions for this group are similar to those in liberal market economies, i.e. they are much more exposed to market forces with fewer institutional buffers.

Almost all changes in employment situations were associated with increased feelings of job insecurity; the income effects were less pronounced. Compared to those continuing to work on-site, employees in all clusters experienced a significant decrease in job security, including employees who continuously worked from home, although they represent the most highly qualified group of employees. Only those who changed from remote work to working on-site did not assess their job security significantly differently from employees who have continuously worked on-site. Significant reductions in household income emerge for employees in continuous short-time work, in unemployment and for those in transitional furlough. As the latter two groups included high shares of individuals with previously low income, a further reduction in household income is especially severe for them.

Our study can only provide a snapshot of the employment consequences and long-term development of inequality associated with the COVID-19 pandemic. Furthermore, our analysis is limited by the low case numbers for specific subgroups such as young labour market entrants and migrants. Therefore, further research is needed to monitor long-term employment changes and to better understand the situation for specific subgroups of employees. Despite these limitations, our results make clear that the pandemic's impact on labour market inequality is different from that of previous recessions. The low-wage segment of the service sector, the recent expansion 
of which has been strongly promoted by political reforms, was largely exempt in the Great Recession, which helped conceal the adverse conditions in that sector. The pandemic has hit these groups of labour market outsiders the hardest. Nor are highly qualified employees spared from the new insecurities, as shown by the higher sense of job insecurity reported by continuous homeworkers. Therefore, the usual government crisis measures that address a decline in large manufacturing companies and a focus on male industrial workers need to be adapted to the pandemic crisis.

\section{References}

Abbott, A (1995) Sequence analysis: New methods for old ideas. Annual review of Sociology 21(1): 93-113.

Adams-Prassl A, Boneva T, Golin M, et al. (2020) Furloughing. Fiscal Studies 41(3): 591-622. DOI: https://doi.org/10.1111/1475-5890.12242.

Adams-Prassl A, Boneva T, Golin M, et al. (2020) Working from home: The polarising workplace. In: VoxEU.org. Available at: https://voxeu.org/article/workinghome-polarising-workplace (accessed 6 November 2020).

Alon T, Doepke M, Olmstead-Rumsey J, et al. (2020) This Time It's Different: The Role of Women's Employment in a Pandemic Recession. w27660, August.

Cambridge, MA: National Bureau of Economic Research. DOI: $10.3386 / \mathrm{w} 27660$.

Anger S, Bauer A, Bossler M, et al. (2020) Befunde der IAB-Forschung zur CoronaKrise - Zwischenbilanz und Ausblick. Available at:

http://doku.iab.de/grauepap/2020/IAB_Befunde_COVID-19.pdf (accessed 10 December 2020).

Blom AG, Gathmann C and Krieger U (2015) Setting Up an Online Panel Representative of the General Population: The German Internet Panel. Field Methods 27(4): 391-408. DOI: 10.1177/1525822X15574494.

Blom AG, Cornesse C, Friedel S, et al. (2020) High Frequency and High Quality Survey Data Collection: Survey Research Methods 14(2). 2: 171-178. DOI: 10.18148/srm/2020.v14i2.7735.

Blossfeld H-P and Mayer KU (1988) Arbeitsmarktsegmentation in der Bundesrepublik Deutschland: Eine empirische Überprüfung von Segmentationstheorien aus der Perspektive des Lebenslaufs. Kölner Zeitschrift für Soziologie und Sozialpsychologie : KZfSS 40(2): 262-283. 
Blundell R, Dias MC, Joyce R, et al. (2020) COVID-19 and Inequalities. Fiscal Studies 41(2): 291-319. DOI: https://doi.org/10.1111/1475-5890.12232.

Bosch G and Weinkopf C (eds) (2008) Low-Wage Work in Germany. The Russell Sage Foundation case studies of job quality in advanced economies. New York: Russell Sage Foundation.

Bothfeld DS (2007) Labour Market Institutions in Germany: Current Status and Ongoing Reforms. WSI-Diskussionspapier 152. Düsseldorf: WSI.

Brülle J, Gangl M, Levanon A, et al. (2018) Changing labour market risks in the service economy: Low wages, part-time employment and the trend in working poverty risks in Germany. Journal of European Social Policy: 0958928718779482. DOI: $10.1177 / 0958928718779482$.

Bundesministerium für Arbeit und Soziales (BMAS) (2020) Erfolgsmodell Kurzarbeit wird verlängert. Available at:

https://www.bmas.de/DE/Presse/Pressemitteilungen/2020/erfolgsmodellkurzarbeit-wird-verlaengert.html (accessed 10 December 2020).

Burda MC and Hunt J (2011) What Explains the German Labor Market Miracle in the Great Recession? Working Paper Series 17187, Working Paper, June. National Bureau of Economic Research. DOI: 10.3386/w17187.

Daly M, Ebbinghaus B, Lehner L, et al. (2020) Oxford Supertracker: The Global Directory for COVID Policy Trackers and Surveys, Department of Social Policy and Intervention. Available at: https://supertracker.spi.ox.ac.uk/.

DiPrete TA (2016) Labor Markets, Inequality, and Change: A European Perspective. Work and Occupations. Sage PublicationsSage CA: Thousand Oaks, CA. DOI: 10.1177/0730888405274511.

Eichhorst W and Marx P (2011) Reforming German labour market institutions: A dual path to flexibility: Journal of European Social Policy. SAGE PublicationsSage UK: London, England. DOI: 10.1177/0958928710385731.

Emmenegger P (2012) The Age of Dualization: The Changing Face of Inequality in Deindustrializing Societies. Oxford University Press.

Eurostat (2020) Low-wage earners as a proportion of all employees (excluding apprentices) by sex [earn_ses_pub1s]. Available at: https://appsso.eurostat.ec.europa.eu/nui/submitViewTableAction.do (accessed 10 December 2020).

Felstead A and Reuschke D (2020) Homeworking in the UK: Before and During the 2020 Lockdown. WISERD Report. Cardiff: Wales Institute of Social and Economic Research. Available at:

https://wiserd.ac.uk/publications/homeworking-uk-and-during-2020-lockdown.

Fischer G and Schmid G (2020) Arbeitslosigkeit in Europa und den USA unter Covid19: Besser im Korsett einer Versicherungslogik eingeengt oder den Launen eines Präsidialsystems ausgeliefert? EME 2020-001, Working Paper. WZB 
Discussion Paper. Available at: https://www.econstor.eu/handle/10419/222600 (accessed 3 December 2020).

Gabadinho A, Ritschard G, Müller NS, Studer M (2011) Analyzing and Visualizing State Sequences in R with TraMineR. Journal of Statistical Software 40 (4): 137.

Garz M (2013) Labour Market Segmentation: Standard and Non-Standard Employment in Germany. German Economic Review 14(3): 349-371. DOI: 10.1111/geer.12008.

Grabka M M, Braband C and Göbler K (2020) Beschäftigte in Minijobs sind VerliererInnen der coronabedingten Rezession. 45/2020, DIW Wochenbericht 45/2020, 11 April. Berlin: DIW Berlin. DOI: 10.18723/diw_wb:2020-45-1.

Hall PA and Soskice DW (2001) Varieties of Capitalism: The Institutional Foundations of Comparative Advantage. Oxford [England] ; New York: Oxford University Press.

Hassel A (2014) The Paradox of Liberalization - Understanding Dualism and the Recovery of the German Political Economy. British Journal of Industrial Relations 52(1): 57-81. DOI: https://doi.org/10.1111/j.1467-8543.2012.00913.x.

Häusermann S and Schwander H (2012) Varieties of Dualization: Identifying Insiders and Outsiders across Regimes. In: Emmenegger P, Häusermann S, Palier B, et al. (eds) The Age of Dualization. Oxford; New York: Oxford University Press. Available at: https://www.mwpweb.eu/SiljaHaeusermann/publication_943.html (accessed 3 December 2020).

Kalina T (2012) Niedriglohnbeschäftigte in der Sackgasse ? - Was die Segmentationstheorie zum Verständnis des Niedriglohnsektors in Deutschland beitragen kann. Available at: https://duepublico2.unidue.dereceive/duepublico_mods_00028473 (accessed 3 December 2020).

Kirchmann A and Rosemann M (2010) Wer sind die Betroffenen der Krise? Parallelen und Unterschiede zur vorangegangenen Krise. WSI-Mitteilungen 63(11): 560568. DOI: 10.5771/0342-300X-2010-11-560.

Konle-Seidl R (2020) Kurzarbeit in Europa: Die Rettung in der aktuellen Corona-Krise? IAB-Forschungsbericht 4/2020: 19.

Lejeune O (2020) Coronavirus counter-measures tracker. Available at: https://coronavirusmeasures.herokuapp.com/.

Lott Y and Abendroth A-K (2020) The non-use of telework in an ideal worker culture: why women perceive more cultural barriers. Community, Work \& Family. Routledge. DOI: 10.1080/13668803.2020.1817726.

Möhring K, Naumann E, Reifenscheid M, Blom AG, et al. (2020) Inequality in employment during the Corona lockdown: Evidence from Germany. In: JESP European Social Policy Blog. Available at: https://rb.gy/jp2kmv (accessed 31 July 2020). 
Naumann E, Möhring K, Reifenscheid M, et al. (2020) COVID-19 policies in Germany and their social, political, and psychological consequences. European Policy Analysis n/a(n/a). DOI: 10.1002/epa2.1091.

Piccarreta R, and Billari FC (2007) Clustering work and family trajectories by using a divisive algorithm. Journal of the Royal Statistical Society: Series A (Statistics in Society) 170 (4): 1061-78.

Rinne U and Zimmermann KF (2012) Another economic miracle? The German labor market and the Great Recession. IZA Journal of Labor Policy 1(1): 3. DOI: 10.1186/2193-9004-1-3.

Rueda D (2012) Dualization and Crisis. Swiss Political Science Review 18(4): 523-530. DOI: $10.1111 /$ spsr.12012.

Rueda D (2014) Dualization, crisis and the welfare state. Socio-Economic Review 12(2). Oxford Academic: 381-407. DOI: 10.1093/ser/mwu015.

Schwander H and Häusermann S (2013) Who is in and who is out? A risk-based conceptualization of insiders and outsiders. Journal of European Social Policy 23(3): 248-269. DOI: 10.1177/0958928713480064.

Sozialpolitik-aktuell (2020a) Zugänge an Arbeitslosen 2005 - 2019. Institut Arbeit und Qualifikation. Available at: http://www.sozialpolitikaktuell.de/tl_files/sozialpolitikaktuell/_Politikfelder/Arbeitsmarkt/Datensammlung/PDF-Dateien/abbIV78.pdf (accessed 12 November 2020).

Sozialpolitik-aktuell (2020b) Eckdaten zum Arbeitsmarkt 2007 - 2019. Institut Arbeit und Qualifikation. Available at: http://www.sozialpolitikaktuell.de/tl_files/sozialpolitikaktuell/_Politikfelder/Arbeitsmarkt/Datensammlung/PDF-Dateien/tabIV1.pdf (accessed 12 November 2020).

Wachter T von (2020) Lost Generations: Long-Term Effects of the COVID-19 Crisis on Job Losers and Labour Market Entrants, and Options for Policy*. Fiscal Studies 41(3): 549-590. DOI: https://doi.org/10.1111/1475-5890.12247.

Wiesner DC (2020) Das Konjunkturpaket der Bundesregierung und seine Auswirkungen auf Frauen und Männer. i3 -Kasseler Diskussionspapiere 9. Available at: https://www.unikassel.de/fb05/fileadmin/datas/fb05/i3DiskussionsPapiere_92020_Wiesner_031220_02.pdf. 


\section{Appendix}

Table A.1. Overview of included variables

\begin{tabular}{llllll}
\hline Variable & N & Mean & Std. Dev. & Min & Max \\
\hline Gender: female & 2,294 & 0.47 & 0.50 & 0 & 1 \\
\hline Age & 2,293 & 46.24 & 11.32 & 19 & 67 \\
\hline Migration background & & & & & \\
\hline No & 2,207 & 0.92 & 0.27 & 0 & 1 \\
\hline Yes & 2,207 & 0.08 & 0.27 & 0 & 1 \\
\hline Health status: poor & 2,120 & 0.03 & 0.18 & 0 & 1 \\
\hline Educational degree & & & & & \\
\hline Low & 2,249 & 0.10 & 0.30 & 0 & 1 \\
\hline Medium & 2,249 & 0.32 & 0.47 & 0 & 1 \\
\hline High & 2,249 & 0.58 & 0.49 & 0 & 1 \\
\hline Sector & & & & & \\
\hline Industry & 2,076 & 0.22 & 0.42 & 0 & 1 \\
\hline Service & 2,076 & 0.34 & 0.47 & 0 & 1 \\
\hline Public & 2,076 & 0.31 & 0.46 & 0 & 1 \\
\hline Other & 2,076 & 0.13 & 0.34 & 0 & 1 \\
\hline Personal net income & & & & & \\
\hline Below 1,000 Euro & 1,871 & 0.48 & 0.50 & 0 & 1 \\
\hline 1,000-2,500 Euro & 1,871 & 0.11 & 0.32 & 0 & 1 \\
\hline Above 2,500 Euro & 1,871 & 0.41 & .049 & 0 & 1 \\
\hline Household income change February-June & 1,774 & 0.12 & 1.60 & -10 & 8 \\
\hline Covid-19 infection: confirmed or very likely & 2,297 & 0.02 & 0.15 & 0 & 1 \\
\hline Subjective unemployment risk change & 1,797 & 0.21 & 0.70 & -4 & 4 \\
February-June & & & & & \\
\hline & & & & \\
\hline & & & & \\
\hline & & & & \\
\hline
\end{tabular}

Source: German Internet Panel, own estimations. 
Table A.2. Multinomial logit regressions for cluster composition, relative risk ratios

\begin{tabular}{|c|c|c|c|}
\hline Reference group: Continuous on-site & (1) & (2) & (3) \\
\hline $\begin{array}{l}\text { Continuous remote work } \\
\text { Gender: female }\end{array}$ & $\begin{array}{l}0.795^{+} \\
(-1.82)\end{array}$ & $\begin{array}{c}0.847 \\
(-1.22)\end{array}$ & $\begin{array}{l}1.027 \\
(0.17)\end{array}$ \\
\hline Age & $\begin{array}{c}0.994 \\
(-1.12)\end{array}$ & $\begin{array}{l}0.993 \\
(-1.21)\end{array}$ & $\begin{array}{l}0.990^{+} \\
(-1.65)\end{array}$ \\
\hline Migration background & $\begin{array}{c}0.904 \\
(-0.42)\end{array}$ & $\begin{array}{c}0.902 \\
(-0.41)\end{array}$ & $\begin{array}{c}0.902 \\
(-0.39)\end{array}$ \\
\hline Health status: poor & $\begin{array}{l}1.204 \\
(0.48)\end{array}$ & $\begin{array}{l}1.158 \\
(0.37)\end{array}$ & $\begin{array}{l}1.176 \\
(0.40)\end{array}$ \\
\hline Educational degree $(\mathrm{RC}=\mathrm{low})$ & $\begin{array}{l}1 \\
(.)\end{array}$ & $\begin{array}{l}1 \\
(.)\end{array}$ & $\begin{array}{l}1 \\
(.)\end{array}$ \\
\hline medium & $\begin{array}{l}1.510 \\
(1.23)\end{array}$ & $\begin{array}{l}1.567 \\
(1.33)\end{array}$ & $\begin{array}{l}1.825 \\
(1.63)\end{array}$ \\
\hline high & $\begin{array}{c}6.758^{* * *} \\
(6.04)\end{array}$ & $\begin{array}{c}7.215^{* * *} \\
(6.18)\end{array}$ & $\begin{array}{c}6.717^{* * * *} \\
(5.41)\end{array}$ \\
\hline Sector ( $R C=$ industry) & & $\begin{array}{l}1 \\
\text { (.) }\end{array}$ & $\begin{array}{l}1 \\
\text { (.) }\end{array}$ \\
\hline service & & $\begin{array}{c}1.792^{* * *} \\
(3.29)\end{array}$ & $\begin{array}{c}2.132^{* * * *} \\
(3.92)\end{array}$ \\
\hline public/education/health & & $\begin{array}{l}0.767 \\
(-1.34)\end{array}$ & $\begin{array}{c}0.826 \\
(-0.90)\end{array}$ \\
\hline other & & $\begin{array}{l}1.254 \\
(0.96)\end{array}$ & $\begin{array}{l}1.394 \\
(1.30)\end{array}$ \\
\hline $\begin{array}{l}\text { Personal net income }(\mathrm{RC}=1000-2500 \\
\text { Euro) }\end{array}$ & & & $\begin{array}{l}1 \\
\text { (.) }\end{array}$ \\
\hline$<1000$ Euro & & & $\begin{array}{c}0.786 \\
(-0.82)\end{array}$ \\
\hline$>2500$ Euro & & & $\begin{array}{c}1.803^{* * * *} \\
(3.71)\end{array}$ \\
\hline Constant & $\begin{array}{c}0.166^{* * *} \\
(-4.27)\end{array}$ & $\begin{array}{c}0.137^{* * *} \\
(-4.46)\end{array}$ & $\begin{array}{c}0.102^{* * *} \\
(-4.73)\end{array}$ \\
\hline $\begin{array}{l}\text { Transitional remote work } \\
\text { Gender: female }\end{array}$ & $\begin{array}{c}0.902 \\
(-0.62)\end{array}$ & $\begin{array}{c}0.746 \\
(-1.63)\end{array}$ & $\begin{array}{l}1.046 \\
(0.22)\end{array}$ \\
\hline Age & $\begin{array}{l}0.983^{*} \\
(-2.36)\end{array}$ & $\begin{array}{l}0.981^{*} \\
(-2.47)\end{array}$ & $\begin{array}{l}0.974^{* *} \\
(-3.09)\end{array}$ \\
\hline
\end{tabular}


Migration background

Health status: poor

Educational degree $(\mathrm{RC}=\mathrm{low})$

medium

high

Sector $(\mathrm{RC}=$ industry $)$

service

public/education/health

other

Personal net income $(\mathrm{RC}=1000-2500$

Euro)

$<1000$ Euro

>2500 Euro

$\begin{array}{ccc}0.763 & 0.834 & 0.892 \\ (-0.81) & (-0.52) & (-0.32) \\ & & \\ 0.706 & 0.709 & 0.784 \\ (-0.55) & (-0.54) & (-0.38)\end{array}$

1

(.)

1.137

(0.29)

$4.869^{* * *}$

(3.90)

$4.078^{* * *}$

(3.41)

$2.976^{* *}$

(2.59)

1

(.)

(.)

0.964

1.160

$(-0.14)$

(0.53)

$1.999^{* *}$

$2.003^{* *}$

(2.84)

(2.68)

1.052

1.136

(0.15)

(0.35)

\section{1}

(.)

$0.368^{+}$

$2.289^{* * *}$

(3.99)

\begin{tabular}{lccc} 
Constant & $\begin{array}{c}0.166^{* * *} \\
(-3.33)\end{array}$ & $\begin{array}{c}0.170^{* *} \\
(-3.09)\end{array}$ & $\begin{array}{c}0.170^{* *} \\
(-2.98)\end{array}$ \\
\hline $\begin{array}{l}\text { Continuous short-time } \\
\text { Gender: female }\end{array}$ & $\begin{array}{c}0.728^{+} \\
(-1.78)\end{array}$ & $\begin{array}{c}1.125 \\
(0.61)\end{array}$ & $\begin{array}{c}1.291 \\
\end{array}$ \\
& & & $(1.15)$ \\
Age & $0.978^{* *}$ & $0.980^{*}$ & $0.979^{*}$ \\
& $(-2.87)$ & $(-2.45)$ & $(-2.44)$ \\
Migration background & 1.368 & 1.291 & 1.264 \\
& $(1.02)$ & $(0.79)$ & $(0.70)$ \\
Health status: poor & 1.194 & & \\
& $(0.32)$ & $(-0.25)$ & $(-0.11)$
\end{tabular}

Educational degree $(\mathrm{RC}=\mathrm{low})$
1

(.)
(.) 
medium

$\begin{array}{ccc}0.669 & 0.728 & 0.723 \\ (-1.45) & (-1.12) & (-1.08) \\ & & \\ 0.816 & 0.984 & 0.921 \\ (-0.76) & (-0.06) & (-0.28)\end{array}$

Sector (RC=industry)

1

(.)

(.)

service

$0.642^{*}$

$0.678^{+}$

$(-2.12)$

$(-1.75)$

public/education/health

$\begin{array}{cc}0.0912^{* * *} & 0.0765^{* * *} \\ (-6.36) & (-6.09) \\ 0.545^{*} & 0.554^{+} \\ (-2.11) & (-1.92)\end{array}$

Personal net income $(\mathrm{RC}=1000-2500$

Euro)

(.)

$<1000$ Euro

1.047

(0.13)

$>2500$ Euro

1.225

Constant

0.699

0.908

0.854

$(-0.79)$

$(-0.20)$

$(-0.31)$

Transitional short-time

Gender: female

1.056

1.342

1.584

$(0.22)$

(1.13)

(1.51)

Age

$0.978^{*}$

0.982

$0.978^{+}$

$(-2.06)$

$(-1.63)$

$(-1.84)$

Migration background

$2.244^{*}$

$2.272^{*}$

$2.093^{+}$

(2.17)

(2.15)

(1.83)

Health status: poor

$$
\begin{aligned}
& 1.972 \\
& (1.07)
\end{aligned}
$$

1.725

1.992

(0.85)

(1.06)

Educational degree $(\mathrm{RC}=$ low $)$

$$
1
$$

(.)

$$
1
$$

(.)

medium

0.589

$(-1.59)$

0.882

$(-0.35)$

0.682

$(-1.02)$

high

$0.344^{* * *}$

$(-3.05)$

0.586

$0.490^{+}$

$(-1.43)$

$(-1.80)$

Sector ( $\mathrm{RC}=$ industry)

1

(.)

(.) 
service

public/education/health

$0.134^{* * *}$

$0.107^{* * *}$

$(-3.93)$

other

0.909

0.864

$(-0.26)$

Personal net income $(\mathrm{RC}=1000-2500$

Euro)

$<1000$ Euro

$>2500$ Euro

\section{Constant \\ Continuous furlough}

0.416

$(-1.44)$

$0.329^{+}$

0.470

Gender: female

$2.851^{* * *}$

$(-1.69)$

Age

(4.15)

$2.128^{* *}$

$1.708^{+}$

$1.034^{* *}$

(2.84)

(1.70)

Age

$1.035^{* *}$

$1.046^{* * *}$

Migration background

$$
0.534
$$

(2.84)

(3.51)

$(-1.03)$

0.570

$(-0.92)$

0.701

$(-0.57)$

Health status: poor

$4.824^{* * *}$

(3.71)

$4.158^{* *}$

$3.768^{* *}$

(3.18)

(2.78)

Educational degree (RC=low)

\section{1}

(.)

1

1

(.)

(.)

medium

0.818
$(-0.47)$

0.875

1.242

$(-0.30)$

(0.41)

high

1.557

(1.08)

1.468

(0.87)

2.233

(1.55)

Sector ( $R C=$ industry)

1

1

(.)

(.)

service

1.670

1.281

(1.12)

(0.52)

public/education/health

$3.180^{* *}$

$2.484^{*}$

(2.67)

(2.04)

other 
Personal net income $(\mathrm{RC}=1000-2500$

Euro)

(.)

$<1000$ Euro

$>2500$ Euro

\begin{tabular}{|c|c|c|c|}
\hline Constant & $\begin{array}{c}0.00765^{* * *} \\
(-6.45)\end{array}$ & $\begin{array}{c}0.00434^{* * *} \\
(-6.39) \\
\end{array}$ & $\begin{array}{r}0.00193^{* * *} \\
(-6.71) \\
\end{array}$ \\
\hline \multicolumn{4}{|l|}{ Transitional furlough } \\
\hline Gender: female & $\begin{array}{l}1.366 \\
(1.57)\end{array}$ & $\begin{array}{l}1.214 \\
(0.89)\end{array}$ & $\begin{array}{c}0.984 \\
(-0.06)\end{array}$ \\
\hline Age & $\begin{array}{c}0.996 \\
(-0.44)\end{array}$ & $\begin{array}{c}0.995 \\
(-0.49)\end{array}$ & $\begin{array}{c}0.995 \\
(-0.48)\end{array}$ \\
\hline Migration background & $\begin{array}{l}1.580 \\
(1.36)\end{array}$ & $\begin{array}{l}1.341 \\
(0.77)\end{array}$ & $\begin{array}{l}1.287 \\
(0.62)\end{array}$ \\
\hline Health status: poor & $\begin{array}{l}1.984 \\
(1.34)\end{array}$ & $\begin{array}{l}1.613 \\
(0.86)\end{array}$ & $\begin{array}{l}1.732 \\
(0.97)\end{array}$ \\
\hline Educational degree $(\mathrm{RC}=\mathrm{low})$ & $\begin{array}{l}1 \\
\text { (.) }\end{array}$ & $\begin{array}{l}1 \\
\text { (.) }\end{array}$ & $\begin{array}{l}1 \\
\text { (.) }\end{array}$ \\
\hline medium & $\begin{array}{l}0.561^{+} \\
(-1.93)\end{array}$ & $\begin{array}{l}0.570^{+} \\
(-1.82)\end{array}$ & $\begin{array}{c}0.670 \\
(-1.22)\end{array}$ \\
\hline high & $\begin{array}{c}0.621 \\
(-1.62)\end{array}$ & $\begin{array}{l}0.536^{*} \\
(-2.00)\end{array}$ & $\begin{array}{l}0.544^{+} \\
(-1.78)\end{array}$ \\
\hline Sector ( $\mathrm{RC}=$ industry) & & $\begin{array}{l}1 \\
\text { (.) }\end{array}$ & $\begin{array}{l}1 \\
\text { (.) }\end{array}$ \\
\hline service & & $\begin{array}{l}1.852^{+} \\
(1.89)\end{array}$ & $\begin{array}{l}1.888^{+} \\
(1.82)\end{array}$ \\
\hline public/education/health & & $\begin{array}{l}2.030^{*} \\
(2.14)\end{array}$ & $\begin{array}{l}2.099^{*} \\
(2.09)\end{array}$ \\
\hline other & & $\begin{array}{l}1.648 \\
(1.26)\end{array}$ & $\begin{array}{l}1.504 \\
(0.94)\end{array}$ \\
\hline
\end{tabular}

Personal net income $(\mathrm{RC}=1000-2500$

Euro)

$<1000$ Euro 


\begin{tabular}{|c|c|c|c|}
\hline Constant & $\begin{array}{l}0.198^{* *} \\
(-3.02)\end{array}$ & $\begin{array}{c}0.136^{* * *} \\
(-3.30)\end{array}$ & $\begin{array}{c}0.117^{* * *} \\
(-3.40)\end{array}$ \\
\hline \multicolumn{4}{|l|}{ Unemployment } \\
\hline Gender: female & $\begin{array}{l}1.396 \\
(1.39)\end{array}$ & $\begin{array}{l}1.478 \\
(1.47)\end{array}$ & $\begin{array}{c}0.603 \\
(-1.55)\end{array}$ \\
\hline Age & $\begin{array}{c}0.993 \\
(-0.66)\end{array}$ & $\begin{array}{l}1.009 \\
(0.71)\end{array}$ & $\begin{array}{l}1.024^{+} \\
(1.84)\end{array}$ \\
\hline Migration background & $\begin{array}{l}1.501 \\
(0.96)\end{array}$ & $\begin{array}{l}1.032 \\
(0.06)\end{array}$ & $\begin{array}{l}1.051 \\
(0.10)\end{array}$ \\
\hline Health status: poor & $\begin{array}{c}8.079^{* * *} \\
(5.38)\end{array}$ & $\begin{array}{c}6.389^{* * *} \\
(4.43)\end{array}$ & $\begin{array}{c}5.935^{* * *} \\
(3.87)\end{array}$ \\
\hline Educational degree $(\mathrm{RC}=\mathrm{low})$ & $\begin{array}{l}1 \\
(.)\end{array}$ & $\begin{array}{l}1 \\
(.)\end{array}$ & $\begin{array}{l}1 \\
(.)\end{array}$ \\
\hline medium & $\begin{array}{l}0.507^{+} \\
(-1.91)\end{array}$ & $\begin{array}{c}0.706 \\
(-0.92)\end{array}$ & $\begin{array}{c}0.713 \\
(-0.80)\end{array}$ \\
\hline high & $\begin{array}{l}0.558^{+} \\
(-1.67)\end{array}$ & $\begin{array}{c}0.827 \\
(-0.50)\end{array}$ & $\begin{array}{l}1.301 \\
(0.62)\end{array}$ \\
\hline Sector (RC=industry) & & $\begin{array}{l}1 \\
(.)\end{array}$ & $\begin{array}{l}1 \\
(.)\end{array}$ \\
\hline service & & $\begin{array}{l}1.150 \\
(0.38)\end{array}$ & $\begin{array}{c}0.927 \\
(-0.18)\end{array}$ \\
\hline public/education/health & & $\begin{array}{c}0.576 \\
(-1.28)\end{array}$ & $\begin{array}{c}0.709 \\
(-0.73)\end{array}$ \\
\hline other & & $\begin{array}{l}2.981^{* *} \\
(2.89)\end{array}$ & $\begin{array}{l}2.500^{*} \\
(2.09)\end{array}$ \\
\hline \multirow{2}{*}{$\begin{array}{l}\text { Personal net income }(\mathrm{RC}=1000-2500 \\
\text { Euro) }\end{array}$} & & & 1 \\
\hline & & & (.) \\
\hline$<1000$ Euro & & & $\begin{array}{c}6.498^{* * *} \\
(5.57)\end{array}$ \\
\hline$>2500$ Euro & & & $\begin{array}{l}0.343^{*} \\
(-2.46)\end{array}$ \\
\hline Constant & $\begin{array}{l}0.148^{* *} \\
(-2.97) \\
\end{array}$ & $\begin{array}{c}0.0427^{* * *} \\
(-4.15) \\
\end{array}$ & $\begin{array}{c}0.0207^{* * * *} \\
(-4.68) \\
\end{array}$ \\
\hline $\mathrm{N}$ & 2016 & 1890 & 1695 \\
\hline Pseudo-R sq. & 0.0500 & 0.0800 & 0.103 \\
\hline
\end{tabular}

